\title{
Analysis of the sensitivity of the identification method of inability states of rotating systems to the conditions of the experiment
}

\author{
Michał Pająk ${ }^{1,}{ }^{*}$, Dragutin Lisjak ${ }^{2}$, Marcin K luczyk ${ }^{3}$ and Davor K olar ${ }^{2}$ \\ ${ }^{1}$ University of Technology and Humanities in Radom, Faculty of Mechanical Engineering, \\ Stasieckiego Street 54, 26-600 Radom, Poland \\ ${ }^{2}$ University of Zagreb, Faculty of Mechanical Engineering and Naval Architecture, Ivana Lučića \\ Street 5, 10002 Zagreb, Croatia \\ ${ }^{3}$ Polish Naval Academy, Mechanical Electrical Faculty, Śmidowicza Street 69, 81-127 Gdynia, \\ Poland
}

\begin{abstract}
One of the most important subsystems of the vehicles and machines operating currently in industry and transportation are the rotating subsystems. M onitoring of its technical state is an important issue of the engineering and academic research. As a result of the research a lot of new diagnostic methods have been formulated but one of the most important characteristic of them is the ability to industrial implementation. It depends on the insensitivity to disturbance which can arise in real operational environment. In the paper the method formulated by the authors is analysed. This is the method of the identification of inability states of rotating subsystems based on the vibrations analyses in the time domain. It constitutes the system approach to the considered issue. There are three applications of the method described - research on simulation laboratory stand, research on a real technical object conducted in the laboratory and research carried out on a real technical object under the real operation conditions. In each case different accuracy of the ability and inability states identification is achieved. Analysing the differences in accuracy of the method applications the conclusion of its sensitivity to the conditions of the experiment were formulated which are presented in the end of the paper.
\end{abstract}

\section{Introduction}

The analysed method is used to identify the reliability states of the rotating subsystems in different kind of vehicles and machines. It is based on time-domain analysis of the vibrations produced when the operational tasks are accomplished by the technical system. In term of a system reliability and safety, vibrations are primary diagnostic symptoms [1-4].

The main principle of the method consists in treating each time history of vibrations as a real value discrete signal expressed in the time domain. It was also established that the considered signals are impulse signals [5] with limited energy [6]. They can be expressed as points in the $L^{2}\left(t_{0}, t_{k}\right)$ function space, where time $t_{0}$ is a start time and time $t_{k}$ is the end time of the signal. This space is a space of impulse signals with limited energy [7]. Extension of the space with scalar addition, multiplication, and norm described by formula (1), constitutes the normalized linear Hilbert space [8]. The relation of the distance between the point of specified vibration signal and the points of ability or inability states calculated in the formulated space is the criterion of identification the reliability state of the considered technical system.

\footnotetext{
* Corresponding author: m.pajak@uthrad.pl
} 


$$
\|v s\|_{L^{2}}=\sqrt{\int_{0}^{\max \left(t_{k}\right)}|v s(t)|^{2} d t}
$$

where: $\|v s\|_{L^{2}}$ - the norm of space $L^{2}, v s$ - the signal time history

During the first step of the method the vibration signals from the object under consideration are recorded and stored to obtain the set of equal length time histories of the vibrations. The signals are recorded on the system in ability state and on the object in the inability states which should be later identified by the method. For each signal the characteristics [9] presented in the following list are calculated:

1. integral of the signal - I(vsi),

2. mean value of the signal - M(vsi),

3. energy of the signal - E(vsi),

4. mean power of the signal - $\mathrm{P}(\mathrm{vsi})$,

5. 1st order moment of the signal - M1'(vsi),

6. 2nd order moment of the signal - M2'(vsi),

7. 1st order central moment of the signal - C1(vsi),

8. 2nd order central moment of the signal - C2(vsi),

9. 1st order normalized moment of the signal - N1(vsi),

10. 2nd order normalized moment of the signal - N2(vsi),

11. 1 st order normalized central moment of the signal - NC1(vsi),

12. 2nd order normalized central moment of the signal - NC2(vsi),

13. abscissa of signal square gravity centre - G(vsi),

14. signal square variance - V(vsi),

15. signal equivalent diameter - $\mathrm{ED}(\mathrm{vsi})$

16. mean width of signal - MV(vsi)

Subsequently, signals are divided into two sets: the learning data set and the testing data set.

In the second step, analysing the learning data set the uniquely identifying reliability state and the uniquely identifying the type of the inability state (type of failure) characteristics are determined.

If the characteristic is concentrated one and the absolute value of the difference of the characteristic mean value for signals from the group of ability states and mean values of the characteristic for signals from each group of inability states is higher than the sum of standard deviations of the signals characteristics for analysed groups, the characteristic is uniquely identifying the reliability state (2):

$$
\boldsymbol{\sigma}_{D\left(V S_{L A}\right)}+\boldsymbol{\sigma}_{D\left(V S_{A}\right)} \leq\left|\bar{D}\left(V S_{I A}\right)-\bar{D}\left(V S_{A}\right)\right|
$$

where: $D(V S)$ - the characteristic of the vibration signal, $V S_{I A}$ - the group of the vibration signals for inability states, $V S_{A}$ - the group of the vibration signals for ability states.

The characteristic is concentrated if standard deviation $(\sigma)$ of the characteristic value $(D)$ in a group of vibration signals $(V S)$ is lower than $15 \%$ of the mean value (3):

$$
\sigma_{D(V S)} \leq \bar{D}(V S) \cdot 0.15
$$

where: $D(V S)$ - the characteristic of the vibration signal, $V S$ - the group of the vibration signals.

Similarly, if the characteristic is concentrated one and the absolute value of the difference of the characteristic mean value for signals from the group of the selected inability state and mean values of the characteristic for signals from remaining group of inability states was higher than the sum of standard deviations of the signals characteristics 
for analysed groups, the characteristic is uniquely identifying the type of the inability state (type of failure).

The characteristics uniquely identifying the reliability state define the reliability states space (RSS) and the characteristics uniquely identifying the type of the inability state define the inability states space (ISS).

In both defined spaces (RSS and ISS) the vibration signals are expressed as points determined by the values of characteristics - the dimensions of the space. The mean values of the characteristics of learning groups also define points in the space. In this way for ability group of learning signals in RSS space the point of the ability states is defined. Similarly, in RRS space for specified types of failures groups of learning signals the points of specified inability states are defined. Simultaneously, in ISS space, the mean values of the characteristics - the dimensions of this space for specified types of failures groups of learning signals determine the points of specific types of inability states.

To assure the same influence of each characteristic on the identification process all values are transformed according to formula (4)

$$
D_{T}=\frac{D}{\max (D(V S))} \cdot 100
$$

where: $D(V S)$ - the characteristic of the vibration signal, $D$ - the value of the characteristic, $D_{T}$ - the value of the characteristic after transformation [\%].

In the final step of the method, in each space, the distances between the points enumerated above and the points determined for each vibration signal from testing groups are calculated. The distances can be calculated as Euclidian or according to formula (5):

$$
\boldsymbol{\delta}\left(v s_{i}, v s_{j}\right)=1-\max \left(\boldsymbol{\alpha}_{v s_{i}, v s_{j}}^{\prime}\left(\tau \in\left[-t_{k}, t_{k}\right]\right)\right)
$$

where: $\delta\left(v s_{i}, v s_{j}\right)$ - the distance of signals $v s_{i}, v s_{j}$ in space $L^{2}, \alpha^{\prime}{ }_{v s i, v s j}$ - the normalized function of mutual correlation of the signals $v s_{i}, v s_{j}(6)$

$$
\boldsymbol{\alpha}_{v s_{i}, v s_{j}}^{\prime}(\tau)=\frac{\left(\left.\left.\int_{0}^{\max \left(t_{k}\right)} v s_{i}(t)\right|_{t_{0}} ^{t_{k}} \cdot v s_{j}(t-\tau)\right|_{t_{0}} d t\right)^{2}}{\left.\left.\int_{0}^{\max _{k}\left(t_{k}\right)} v s_{i}(t)\right|_{t_{0}} ^{t_{k}{ }^{2}} d t \cdot \int_{0}^{\max \left(t_{k}\right)} v s_{j}(t)\right|_{t_{0}} ^{t_{k}{ }^{2}} d t}
$$

If the distance between the point of RSS space determined for analysed signal and the point of the ability states is smaller than every distances between that point and inability states points, then the signal is identified as registered on rotating subsystem remaining in ability state. Otherwise, the analysed signal is identified as signal registered on rotating subsystem remaining in inability state.

If the signal was classified as a signal registered on rotating subsystem remaining in inability state it was also analysed in ISS space. The signal was identified as a signal recorded on rotating subsystem remaining in specified inability state if the distance between the point of ISS space determined for analysed vibration signal and the point of ISS space determined for one of the considered inability states is the smallest one.

\section{Research on simulation laboratory stand}

In the study [10], the vibration signals acquired from a machine fault simulator were used. A SpectraQuest variable speed M achinery Fault Simulator (MFS) was used to generate both normal operation (NO) and faulty condition data. The simulation stand (Fig. 1) comprised 1 HP variable speed motor driving a shaft-rotor component via coupling supported with two sets of ball bearings. The MFS is outfitted with three-axis accelerometer and a tachometer that were connected to a National Instruments DAQ System. 
Three-axis accelerometer was mounted on the bearing housing on the shaft side opposite of the motor position. The sampling frequency was set to $6,4 \mathrm{kHz}$, while revolving speed during the experiment was $1500 \mathrm{rpm}$. Vibration signals in three directions $(X, Y, Z)$ were acquired when the system operated under normal condition $(\mathrm{NO})$ and faulty conditions (UN). There were four faulty conditions simulated: slant rotor (SR), eccentric rotor (ER), unbalanced rotor without additional load (UR) and unbalanced rotor with additional load $3 \mathrm{~kg}$ along $Z$ axis (URAL).

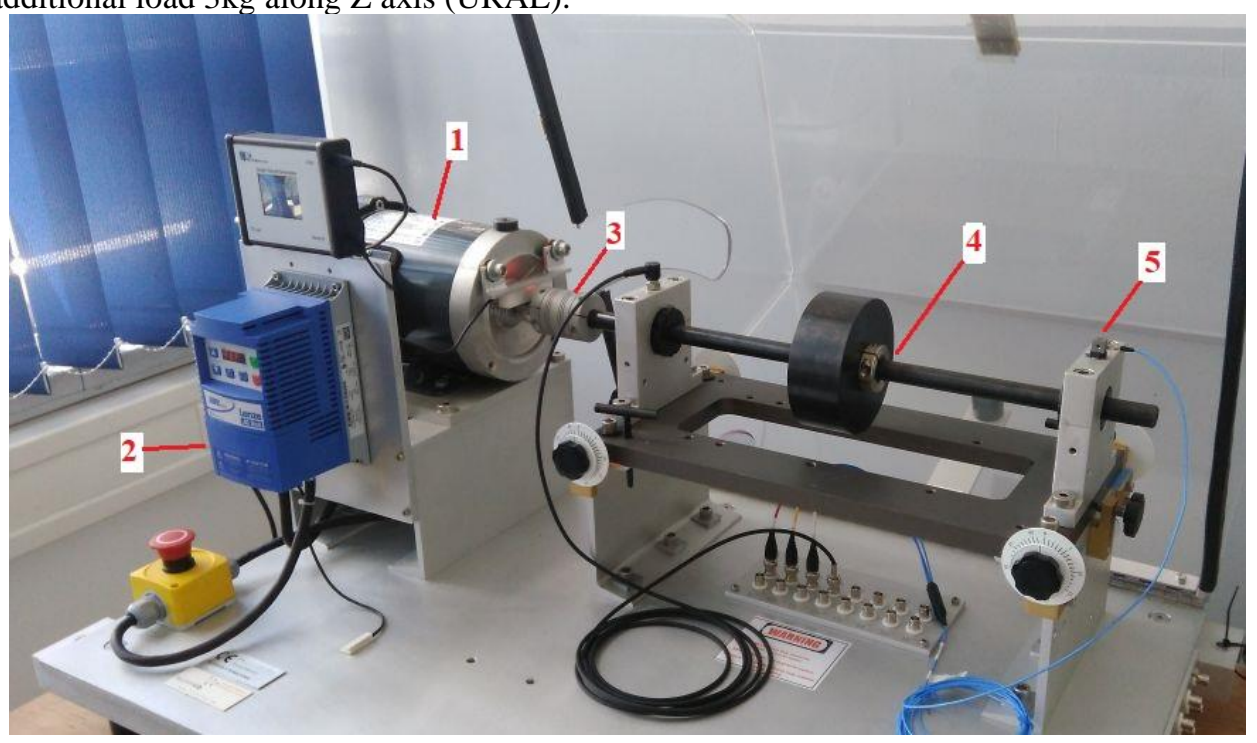

Fig. 1. Fault simulator: 1 - three-phase induction motor, 2 - variable speed motor drive, 3 - clutch, 4 - main shaft with load, 5 - three-axis accel erometer.

According to the implemented method, for recorded vibrations signals, the characteristics values were calculated. Based on the calculations result the concentrated and uniquely identifying characteristics were identified. In table 1 the results of the concentration analysis of the characteristics are presented. In the table 1 means concentrated and 0 not concentrated characteristic.

Having uniquely identifying characteristics specified RSS and ISS states spaces were defined. RSS space was $R^{7}$ and the dimensions of it were the characteristics uniquely identifying the reliability state $X: 1 ; X: 2 ; X: 5 ; X: 6 ; Z: 1 ; Z: 2 ; Z: 5$ (X and $Z$ are the vibrations axis; number is the characteristic according to the numbers in characteristics list). ISS was $R^{4}$ space and dimensions of it were the characteristics uniquely identifying the type of the inability state $X: 3 ; X: 4 ; Y: 3 ; Y: 4$.

In order to test the method accuracy, the distances between points in both spaces were calculated as Euclidian ones. The results of the considered reliability states identification are presented in table 2 .

Table 1. The results of the concentration analysis of the characteristics.

\begin{tabular}{|c|c|c|c|c|c|c|c|c|c|c|c|c|c|c|c|c|}
\hline Axis & \multicolumn{16}{|c|}{$\mathbf{X}$} \\
\hline Ch-k & \multirow[t]{2}{*}{1} & \multirow[t]{2}{*}{2} & \multirow[t]{2}{*}{3} & \multirow[t]{2}{*}{4} & \multirow[t]{2}{*}{5} & \multirow[t]{2}{*}{6} & \multirow[t]{2}{*}{7} & \multirow[t]{2}{*}{8} & \multirow[t]{2}{*}{9} & \multirow[t]{2}{*}{10} & \multirow[t]{2}{*}{11} & \multirow[t]{2}{*}{12} & \multirow[t]{2}{*}{13} & \multirow[t]{2}{*}{14} & \multirow[t]{2}{*}{15} & \multirow[t]{2}{*}{16} \\
\hline Group & & & & & & & & & & & & & & & & \\
\hline NO & 1 & 1 & 0 & 0 & 1 & 1 & 0 & 1 & 1 & 1 & 1 & 1 & 1 & 1 & 0 & 1 \\
\hline SR & 1 & 1 & 1 & 1 & 1 & 1 & 0 & 0 & 1 & 1 & 1 & 1 & 1 & 1 & 0 & 1 \\
\hline ER & 1 & 1 & 1 & 1 & 1 & 1 & 0 & 0 & 1 & 1 & 1 & 1 & 1 & 1 & 0 & 1 \\
\hline UR & 1 & 1 & 1 & 1 & 1 & 1 & 1 & 0 & 1 & 1 & 1 & 1 & 1 & 1 & 0 & 1 \\
\hline
\end{tabular}




\begin{tabular}{|c|c|c|c|c|c|c|c|c|c|c|c|c|c|c|c|c|}
\hline URAL & 1 & 1 & 1 & 1 & 1 & 1 & 1 & 0 & 1 & 1 & 1 & 1 & 1 & 1 & 0 & 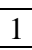 \\
\hline UN & 1 & 1 & 0 & 0 & 1 & 1 & 0 & 0 & 1 & 1 & 1 & 1 & 1 & 1 & 0 & 1 \\
\hline Axis & \multicolumn{16}{|c|}{ Y } \\
\hline NO & 0 & 0 & 1 & 1 & 0 & 0 & 0 & 0 & 0 & 0 & 0 & 0 & 1 & 1 & 0 & 1 \\
\hline SR & 0 & 0 & 1 & 1 & 0 & 0 & 0 & 0 & 1 & 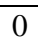 & 1 & 1 & 1 & 1 & 0 & 1 \\
\hline ER & 0 & 0 & 1 & 1 & 0 & 0 & 0 & 0 & 1 & 1 & 1 & 1 & 1 & 1 & 0 & 1 \\
\hline UR & 0 & 0 & 1 & 1 & 0 & 0 & 0 & 0 & 0 & 0 & 0 & 0 & 1 & 1 & 0 & 1 \\
\hline URAL & 0 & 0 & 1 & 1 & 0 & 0 & 0 & 0 & 0 & 0 & 0 & 0 & 1 & 1 & 0 & 1 \\
\hline UN & 0 & 0 & 0 & 0 & 0 & 0 & 0 & 0 & 0 & 0 & 0 & 0 & 1 & 1 & 0 & 1 \\
\hline Axis & \\
\hline NO & 1 & 1 & 1 & 1 & 1 & 1 & 0 & 0 & 1 & 1 & 1 & 1 & 1 & 1 & 0 & 1 \\
\hline SR & 1 & 1 & 1 & 1 & 1 & 1 & 0 & 1 & 1 & 1 & 1 & 1 & 1 & 1 & 0 & 1 \\
\hline ER & 1 & 1 & 1 & 1 & 1 & 1 & 1 & 0 & 1 & 1 & 1 & 1 & 1 & 1 & 0 & 1 \\
\hline UR & 1 & 1 & 1 & 1 & 1 & 1 & 1 & 0 & 1 & 1 & 1 & 1 & 1 & 1 & 0 & 1 \\
\hline URAL & 1 & 1 & 1 & 1 & 1 & 1 & 0 & 0 & 1 & 1 & 1 & 1 & 1 & 1 & 0 & 1 \\
\hline UN & 1 & 1 & 1 & 1 & 1 & 1 & 1 & 0 & 1 & 1 & 1 & 1 & 1 & 1 & 0 & 1 \\
\hline
\end{tabular}

Table 2. The results of the identification process.

\begin{tabular}{|c|c|c|c|c|c|}
\hline \multicolumn{6}{|c|}{ Identification in RSS space } \\
\hline $\begin{array}{c}\text { Group of } \\
\text { testing signals }\end{array}$ & \multicolumn{2}{|c|}{$\begin{array}{c}\text { Identified as ability } \\
\text { state }\end{array}$} & \multicolumn{2}{|c|}{$\begin{array}{l}\text { Identified as } \\
\text { inability state }\end{array}$} & $\begin{array}{l}\text { Correctness of reliability } \\
\text { state identification [\%] }\end{array}$ \\
\hline NOT & \multicolumn{2}{|c|}{148} & \multicolumn{2}{|l|}{2} & 98,7 \\
\hline SRT & \multicolumn{2}{|c|}{0} & \multicolumn{2}{|c|}{25} & 100 \\
\hline ERT & \multicolumn{2}{|c|}{0} & \multicolumn{2}{|c|}{25} & 100 \\
\hline URT & \multicolumn{2}{|c|}{0} & \multicolumn{2}{|c|}{37} & 100 \\
\hline URALT & \multicolumn{2}{|c|}{1} & \multicolumn{2}{|c|}{36} & 97,3 \\
\hline \multicolumn{6}{|c|}{ Identification in ISS space } \\
\hline $\begin{array}{c}\text { Group of } \\
\text { testing signals }\end{array}$ & $\begin{array}{l}\text { Identified } \\
\text { as SR }\end{array}$ & $\begin{array}{l}\text { Identified } \\
\text { as ER }\end{array}$ & $\begin{array}{l}\text { Identified } \\
\text { as UR }\end{array}$ & $\begin{array}{l}\text { Identified } \\
\text { as URAL }\end{array}$ & $\begin{array}{c}\text { Correctness of inability } \\
\text { state type identification } \\
{[\%]}\end{array}$ \\
\hline SRT & 25 & 0 & 0 & 0 & 100 \\
\hline ERT & 0 & 25 & 0 & 0 & 100 \\
\hline URT & 0 & 0 & 37 & 0 & 100 \\
\hline URALT & 0 & 0 & 0 & 36 & 100 \\
\hline
\end{tabular}

It can be noticed that mean accuracy of reliability state identification is equal to $99,2 \%$ while the accuracy of the type of the inability state identification is equal to $100 \%$.

\section{Research on a real technical object conducted on laboratory stand}

Operational tests were carried out in the Laboratory of Ship Engine Room Operation of Mechanical and Electrical Engineering Department of Polish Naval Academy in Gdynia on Sulzer 6AL20/24 engine. This is a 4-stroke high pressure, inline, non-reversing, water cooled diesel engine with a direct fuel injection. The engine is charged with a turbo charger and charging air is cooled. The research object was a clockwise engine with the ignition order 1-4-2-6-3-5, equipped with a multi-scope rotational speed controller of the type Woodward PGA. The tests involved recording vibration signals and intensity of noise generated by the engine. All the records were made for similar performance parameters, that is, for rotational speed of about $750 \mathrm{rpm}$ and torque $3.3 \mathrm{kNm}$. Measurements of vibrations were carried out by means of a head settled on each cylinder to record vibrations in the horizontal direction $\mathrm{H}$ and vertical direction $\mathrm{V}$ and the measurements of noise intensity were carried out by means of a microphone placed at the distance $200 \mathrm{~mm}$ from the central part of the engine. The sampling frequency was $32768 \mathrm{~Hz}$. 


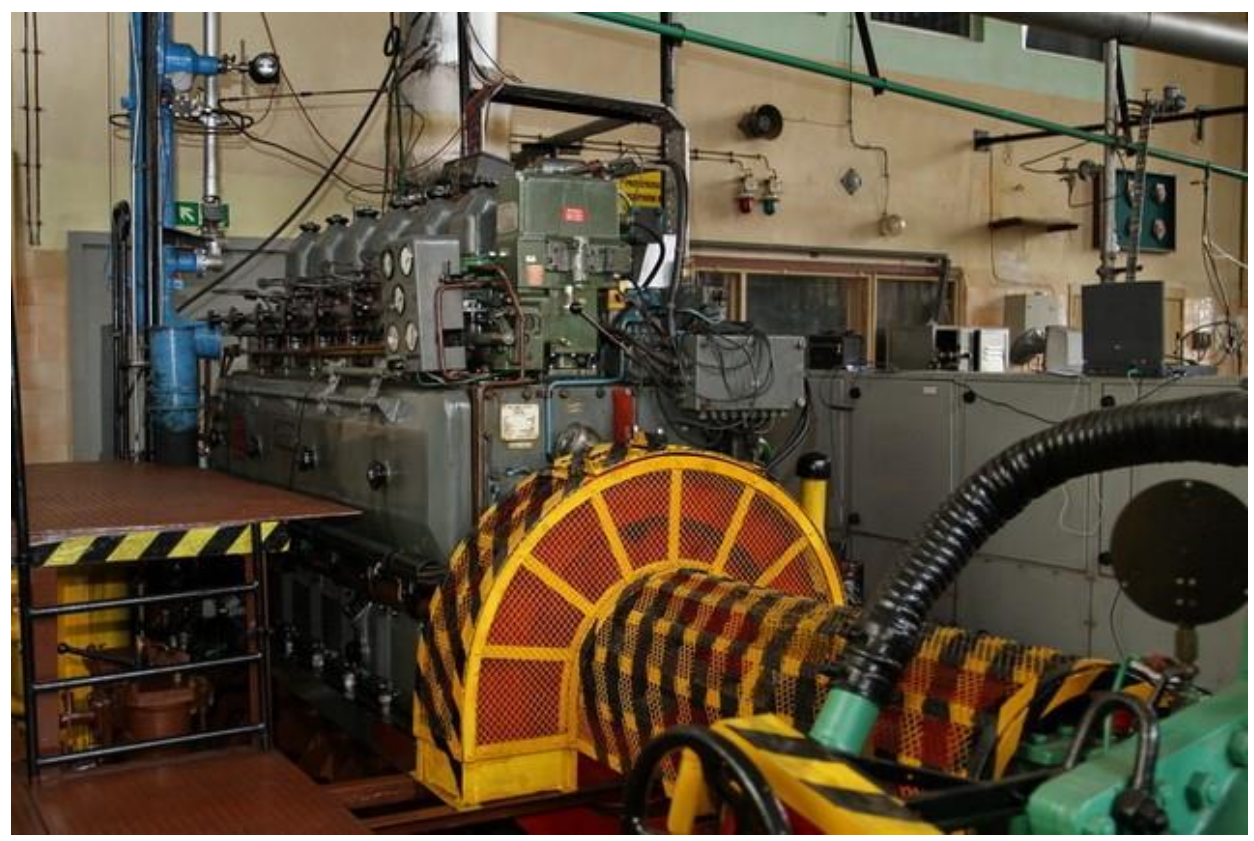

Fig. 2. Sulzer $6 A L 20 / 24$ engine on laboratory stand.

Vibration signals in two directions $(\mathrm{H}, \mathrm{V})$ and noise signal $(\mathrm{N})$ for each cylinder were acquired when the system operated under normal condition (NO) and faulty conditions (UN). There were five faulty conditions simulated: valve clearances reduced to $0.2 \mathrm{~mm}$ on all valves of cylinder 4 (V02), valve clearances of all valves of cylinder 1 increased to 0.8 $\mathrm{mm}$ (V08), valve clearances increased on the exhaust valves of the cylinder 1 (CLE), damage to injection pump of cylinder 1 (PUM) and opening pressure of injector of cylinder 1 decreased to $23 \mathrm{MPa}$ (INJ).

As a result of the analysed method implementation the $R^{4}$ reliability states space (RSS) and $R^{6}$ inability states space (ISS) was formulated. The dimensions of RSS space were the energy of horizontal vibrations for cylinder 1 (H1:3), the mean power of horizontal vibrations for cylinder 1 (H1:4), the energy of horizontal vibrations for cylinder 2 (H2:3) and the mean power of horizontal vibrations for cylinder 2 (H2:4) while the dimensions of ISS space were the energy of vertical vibrations for cylinder 1 (V1:3), the mean power of vertical vibrations for cylinder 1 (V1:4), the energy of horizontal vibrations for cylinder 1 (H1:3), the mean power of horizontal vibrations for cylinder 1 (H1:4), the energy of horizontal vibrations for cylinder 3 (H3:3) and the mean power of horizontal vibrations for cylinder 3 (H3:4).

The distances between points in both spaces were calculated as Euclidian ones. The reached accuracy of the reliability state identification was equal to $100 \%$ but mean accuracy of the type of the inability state identification was $95,5 \%$.

\section{Research carried out on a real technical object under the real operation conditions}

The tests were performed on minesweepers of 207 P type (Fig. 3). Vibrations produced by propeller systems of these ships were main subject of this study [9]. The vessels are tested on the same basin and the research was performed in similar weather conditions with not more than $2^{\circ}$ Beaufort at the sea as waves hitting the hull could cause significant changes in values of the recorded vibrations. Three identical accelerometers (B\&K 4514B) were used for measurements. They were mounted on three perpendicular axes. Measurement tracks 
were calibrated before and after measurements. The whole procedure was carried out according to [11] and the branch norm. All the recorded signals were synchronized by means of a four-channel measurement card cage. Vibration accelerations were recorded in the range of $3.2 \mathrm{kHz}$ band and with sampling frequency 8192 .

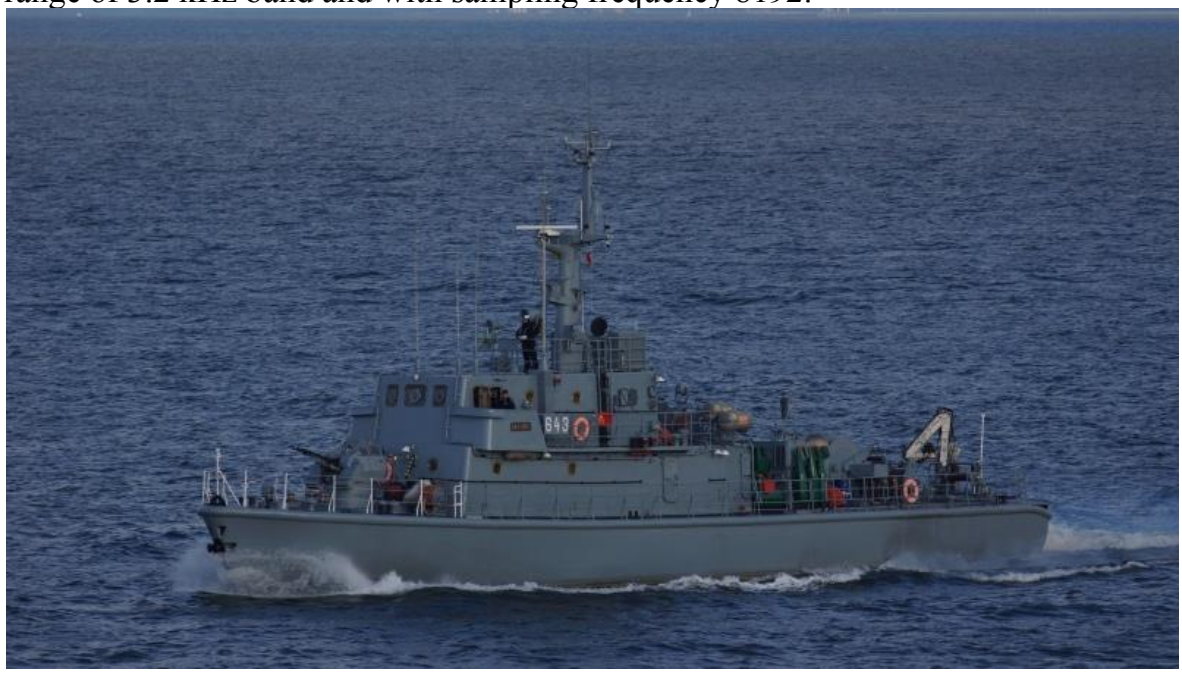

Fig. 3. Research object under tests [12].

The vibration signals were recorded on four vessels, two drive shaft lines of three vessels and one shaft line for one of them and six measurement points on each shaft line. $M$ easurement points were localized on the most important components of shaft lines that is, two on the main engine, one on a hydro-kinetic clutch, two on a reverse reduction transmission and one on a resistance - carrier bearing. Six shaft lines were in the ability state and one was in inability state.

Analysing the characteristics calculated according to the proposed method for the collected signals four of them were taken into further considerations. As it was already mentioned is was performed based on the mean values and standard deviations values calculated for each characteristic (Table 3).

Table 3. M ean values and standard deviations for calculated characteristics.

\begin{tabular}{|c|c|c|c|c|}
\hline \multirow{2}{*}{ Characteristic } & \multicolumn{2}{|c|}{ Line shafts - ability state } & \multicolumn{2}{c|}{ Line shafts - inability state } \\
\cline { 2 - 5 } & Mean value & Standard deviation & Mean value & Standard deviation \\
\hline 1 & -0.22393 & 123.382 & -11.4532 & 162.6791 \\
\hline 2 & -0.00022 & 0.12049 & -0.01118 & 0.158866 \\
\hline 3 & 1180398 & 424768 & 5304218 & 586579.4 \\
\hline 4 & 1152.732 & 414.8125 & 5179.9 & 572.8314 \\
\hline 5 & -1716.63 & 83198.47 & -8242.53 & 117694.5 \\
\hline 6 & -1427536 & 83924578 & -5683411 & $1.19 \mathrm{E}+08$ \\
\hline 7 & -7851078 & 14374029 & $-1.4 \mathrm{E}+07$ & 31992375 \\
\hline 8 & $-3.3 \mathrm{E}+11$ & $3.55 \mathrm{E}+12$ & $-1.6 \mathrm{E}+12$ & $1.07 \mathrm{E}+13$ \\
\hline 9 & 551.6144 & 4041.813 & -3425.82 & 30283.92 \\
\hline 10 & 492605.5 & 4010389 & -1760880 & 16612434 \\
\hline 11 & $-2,4 \mathrm{E}-11$ & $6,23 \mathrm{E}-10$ & $5,61 \mathrm{E}-08$ & $4.45 \mathrm{E}-07$ \\
\hline 12 & $-1.6 \mathrm{E}+07$ & $1.26 \mathrm{E}+08$ & $-9.2 \mathrm{E}+08$ & $7.23 \mathrm{E}+09$ \\
\hline 13 & 512.9525 & 36.52164 & 516.8032 & 30.33512 \\
\hline 14 & 85590.06 & 13983.15 & 85850.59 & 12221.32 \\
\hline 15 & -22.8706 & 290.845 & 0.752316 & 11.16063 \\
\hline
\end{tabular}


The characteristics used to formulate RSS space were mean value of the signal, mean power, mean value of the abscissa of the signal square gravity centre and mean value of the signal square variance. The distances between points in the space were calculated as Euclidian ones. The reached accuracy of the reliability state identification was equal to $75 \%$. In order to increase the accuracy of identification the distance from the reference point calculated according to the formula (5) was taken into consideration as additional characteristic. The subsequent calculations were performed by mean of crisp [13] and fuzzy [14] clusters introduction. Thanks to it the accuracy increased to $79,5 \%$ and $85,5 \%$ respectively.

\section{Summary and Conclusions}

In the paper the method of the rotating subsystems reliability states identification was presented. The accuracy of the method was examined in case of fault simulator laboratory stand, in case of real technical object tested on laboratory stand and in case of operational tests of the selected technical object. The described use cases of the method prove its high accuracy however the influence of the conditions of the experiments can be clearly noticed.

As far as the reliability state identification is concerned (RSS space) the simulations and the laboratory tests reach comparable accuracy on the level $99-100 \%$ but for operational tests the accuracy is significantly lower and at best equals $85,5 \%$. The difference in accuracy is caused by the noise from the environment which cannot be neglected in case of the research performed under real operation conditions. As a result of the analyses it can be stated that the method can be used to reliability state identification but in case of operational tests the noise present in vibration signals should be taken into consideration.

As far as the inability type identification is concerned (ISS space) only simulations and laboratory tests can be compared. In case of simulations $100 \%$ identification accuracy was reached and it slightly $(95,5 \%)$ decreased in laboratory tests. The fall of accuracy occurs due to complexity of the research object. In real ship engine there are a lot of bidirectional connections between elements that can be reason why the vibration signals are blurred. However, even in case of such complex object thanks to the proposed method implementation it was possible to reach relatively high accuracy of the fault type identification what prove the method adequacy.

\section{References}

1. A. F. Molland, The maritime engineering reference book, a guide to ship design, construction and operation (B utterworth-Heinemann, 2011)

2. Ł. Muślewski, Evaluation Method of Transport Systems Operation Quality, Pol. J. Environ. Stud. 18, 2A (2009)

3. M. Woropay, B. Landowski, A. Neubauer, Controlling reliability in the transport systems (B.P.E.-WIEM , BydgoszCz - Radom, 2004)

4. M. Woropay, Ł. Muślewski, Quality in a systemic approach (ITeE, Radom, 2005)

5. T. P. Zieliński, Digital processing of signals. From theory to practice (WKt, W arszawa, 2009)

6. J. Izydorczyk, G. Pionka, G. Tyma, Theory of signals. Introduction 2nd EditionCorrected and amended (Helion, Gliwice, 2006)

7. J. Szabatin, Signal theory fundamentals (WKL, Warszawa, 2007)

8. I. Górniewicz S. Roman, Mathematical Analysis for Physicians (Scientific Publishing Office of Nicolaus Copernicus U niversity of Torun, Torun, 2000)

9. Ł. Muślewski, M. Pająk, A. Grządziela, J. Musiał, Analysis of vibration time histories in the time domain for propulsion systems of minesweepers, J. V ibroengineering, Issue 3, V olume 17 I ssue 3, pp. 1309-1316 (2015) 
10. M. Pająk, D. Lisjak, D. Kolar, Identification of inability states of rotating subsystems of vehicles and machines, J. K ONES, Vol. 26 Issue 1, pp. 111-118 (2019)

11. PN ISO 10816-1

12. http://www.shipspotting.com/gallery/photo.php?lid=2071522

13. A. Grządziela, J. Musiał, Ł. Muślewski, M. Pająk, A method for identification of noncoaxiality in engine shaft lines of a selected type of naval ships, Pol. M arit. Res., V ol. 22 Issue 1, pp. 65-71 (2015)

14. M. Pająk, Ł. Muślewski, B. Landowski, A. Grządziela, Fuzzy identification of the reliability state of the mine detecting ship propulsion system, Pol. M arit. Res., V ol. 26 Issue 1, pp. 55-64 (2019) 